\title{
ROLE OF CENTRAL FATIGUE IN RESISTANCE AND ENDURANCE EXERCISES: AN EMPHASIS ON MECHANISMS AND POTENTIAL SITES
}

\author{
Kimiya Sadri', Mostafa Khani ${ }^{2}$, and Iraj Sadri ${ }^{3}$
}

${ }^{1}$ Education office of Tabriz, Tabriz, Iran 2Department of Physical Education and Sports Sciences, Ahar Branch, Islamic Azad University, Ahar, Iran

32Department of Physical Education and Sports Sciences, Shabestar Branch, Islamic Azad University, Shabestar, Iran

\section{SUMMARY}

An exercise-induced reduction in maximal force production, or the inability to continue an activity with enough force, is defined as fatigue. Although the etiology of fatigue is complex, it can be divided into two distinct components: central and peripheral. Central fatigue is the progressive exerciseinduced loss of the voluntary activation, or decrease in the neural stimulation, of the muscle, thereby reducing maximal force production. Considering the different mechanisms of strength and endurance activities as well as previous research, the authors suggest that there is peripheral fatigue in both kinds of activities. However, the mechanisms of fatigue and the rate of perceived exertion are distinct (mentally, endurance exercise is more difficult). An analysis of fatigue kinetics shows that peripheral fatigue occurs initially, and the central nervous system tries to prevent the disorder via output force through the perceptions of the metabolic condition of the muscle and the activation of additional motor units. Once peripheral fatigue surpasses a certain amount, the central nervous system reduces the number of activated motor units to prevent serious disorders in homeostasis and muscle damage, and protects the central governor. Still, in important and critical situations such as the final stages of running a marathon (when the last flight of runners is observed) and fight-or-flight situations in which someone faces a worse outcome if a task is abandoned, humans can choose one of worse or the worst alternatives to write their final destiny.

Key Words: central fatigue, maximum voluntary contraction, neurotransmitters, temperature, perceived exertion.

\section{INTRODUCTION}

Since long time ago, the fatigue has been considered by human ancestors, battle warriors and athletic champions to prevent or at least delay it by using some substances. Even now, preventing fatigue and performance degradation is the concern of professional athletes who seek colorful medals and championship platforms. This issue needs knowledge of the fatigue's underlying causes and mechanisms. Exercise-induced drop in maximal force production or inability to continue the activity with sufficient force is defined as fatigue. When a series of persistent or frequent contractions is done, the processes that cause muscle fatigue can occur at any part of the muscle to the brain pathways (Taylor, Todd, \& Gandevia, 2006). Although the causes of fatigue are complex, but it can be divided into two distinct components: central and peripheral (Gandevia, 2001). Peripheral fatigue is a reduction in the force generating capacity of the skeletal muscle that may occur within muscle, or at the neuromuscular junction. Peripheral fatigue is determined as a failure or disruption in the conduction of potential action, impairment in excitability of the sarcolemma, excitation-contraction coupling or disturbance in the cross bridge cycle, in the presence 
of increased or unchanged nerve excitation (Gibson, Lambert, \& Noakes, 2001). Central fatigue is a progressive loss of voluntary activation or reduced nervous excitation into muscles and thus decreased maximal force production during exercise (Ross, Middleton, Shave, George, \& Nowicky, 2007). In this review, after a preliminary study of central fatigue, its different aspects will be studied to get a thorough perception of this point of view during different exercises and some ideas to prevent or slow it down.

\section{WHAT IS THE CENTRAL FATIGUE?}

Neuromuscular fatigue can be described as a decline in performance that is usually determined by power generation capacity. During a static maximal contraction, force will decrease steadily and fatigue would be observed from the beginning of the exercise. Contrarily, in submaximal contractions, the target force is preserved for a long time. In this situation, the fatigue is defined as the inability in maintaining the force, even if the capacity of maximal force generation is impaired earlier during contraction. Neuromuscular fatigue is usually defined as a reduction of the capacity of maximal force generation (Gandevia, 2001). Velstad (1997) defined neuromuscular fatigue as any exercise-induced reduction in the maximal capacity of force generation or output force. This definition allows us to define fatigue in different sports and various intensities. In addition, there must be a distinction between the muscle weakness as a chronic disorder in force generation or output force and the acute effect of neuromuscular fatigue. So, it seems that neuromuscular fatigue develops differently depending on the muscle activity (Taylor \& Gandevia, 2008). Fatigue was traditionally related to the metabolic occurrence of ending point during the exercise in which glycogen concentration within the muscle was depleted completely (Bergström, Hermansen, Hultman, \& Saltin, 1967). Furthermore, cardiovascular (González-Alonso \& Calbet, 2003; Rowell, Marx, Bruce, Conn, \& Kusumi, 1966) and metabolic load, and temperature adjustment are likely peripheral candidates for the fatigue outbreak during long exercises (Hargreaves \& Febbraio, 1998).

Sites of neuromuscular fatigue can be divided into two categories: central and peripheral. Central fatigue is considered as any exercise-induced decrease in maximal voluntary contraction force that is associated with a fall in the maximal force generation (Taylor \& Gandevia, 2008) may be caused by the cerebral cortex (reduced descending stimulation or motivation). It can also be derived from spinal cord (a disorder in shooting of alpha motor nerves or submaximal recalling for force generation) (Kent-Braun, 1999; Taylor \& Gandevia, 2008; Taylor et al., 2006). Thus, excitation factors, integrating sensory informa-

\section{TABLE 1}

Fatigue mechanisms associated with CNS disorders.

1. Weakness due to the failure of the motor cortex for recalling the muscle.

2. Poor coordination of motor units shooting.

3. Delayed transmission and disorder in dynamic recruitment.

4. Changes in synergistic muscles cooperation with special forces.

5. The lack of coherence between different central motor nerves or between motor nerves in motor cortex and spinal motor neurons.

6. Changes in connective tissue and joint mobility from spasticity.

7. Muscle atrophy because of denervation.

8. Muscle atrophy, resulting from inactivity.

9. Decreased aerobic phosphorylation of muscle because of physical unfitness.

\section{TABLE 2}

The central fatigue mechanisms (Source: Dobkin, 2008).

1. The lack of high-threshold motor units recalling.

2. Decreased central excitation because of the increased intra neurons inhibitory input to the motor cortex.

3. Obstruction of central guidance as a result of motor nerve demyelination or its dysfunction.

4. Increased negative feedback from type III and IV afferents.

5. The lack of positive feedback from afferent type I of muscle spindle. 
tion and motor signal transmission affect the central fatigue. However, in healthy human, broadcasting motor signals for physiological excitations in normal levels seems to be enough. In Tables 1 and 2, we review the mechanisms proposed for occurring central fatigue.

\section{UNDERLYING MECHANISMS OF CENTRAL FATIGUE}

\section{Protecting the organism and central fatigue}

Why is the brain unable to recruit additional motor units to keep up the activity during long-term exercise?

Prediction of the central governor model during endurance exercises is that the brain does not use extra motor units because such a use could threaten the capacity of preserving the homeostasis which potentially causes to an early ending of exercise in the best case, and organism damage or even death in the worst cases (Noakes, Gibson, \& Lambert, 2005). Findings of isolated muscles suggest that CNS monitors the peripheral state of active muscles through the sensory feedback and uses this information to adjust muscle activation to protect muscle storage capacity. Alternatively, muscle afferents probably disturb slowly the desire or ability of maintaining the high Central motor output (CMO) and therefore, the high-intensity exercises and performance to prevent more development of peripheral fatigue over than the tolerable level which causes exercise to be painful (Figure 1). This model, known as the fatigue nonlinear system is an optimized model which by that fatigue will be felt as unconscious perception of afferent feedback through the different linear model. Brain integrates these afferent signals (which are received because of a severe disruption in homeostasis), in order to protect the organism against damage or death (Abbiss \& Laursen, 2005). Studies have also shown that by increasing the running time, reduction in force may eventually reach a plateau. This could be due to the influence of the central protective mechanism that tries to limit the muscular work during prolonged running to prevent large homeostasis disorders, muscle damage, and biological damages (Noakes, 2000). Gandevia (2001) stated that, CMO reduction as a result of the inhibitory afferent feedback costs to the maximal performance. This regulatory mechanism is suggested as a limiting factor in endurance performance (Ibid). However, this model predicts that the rising feeling of pain increasingly decreases the individual's conscious tendency to stop this mechanism that may cause more motor unit utilization. Thus, the existence of this canceling system is undesirable because it can preserve or increase the intensity of activities that may threaten homeostasis (Noakes et al., 2005).

\section{FIGURE 1}

$V$ isual view of the supraspinal inhibition reflex model in endurance exercise (Source: Dempsey, 2008).

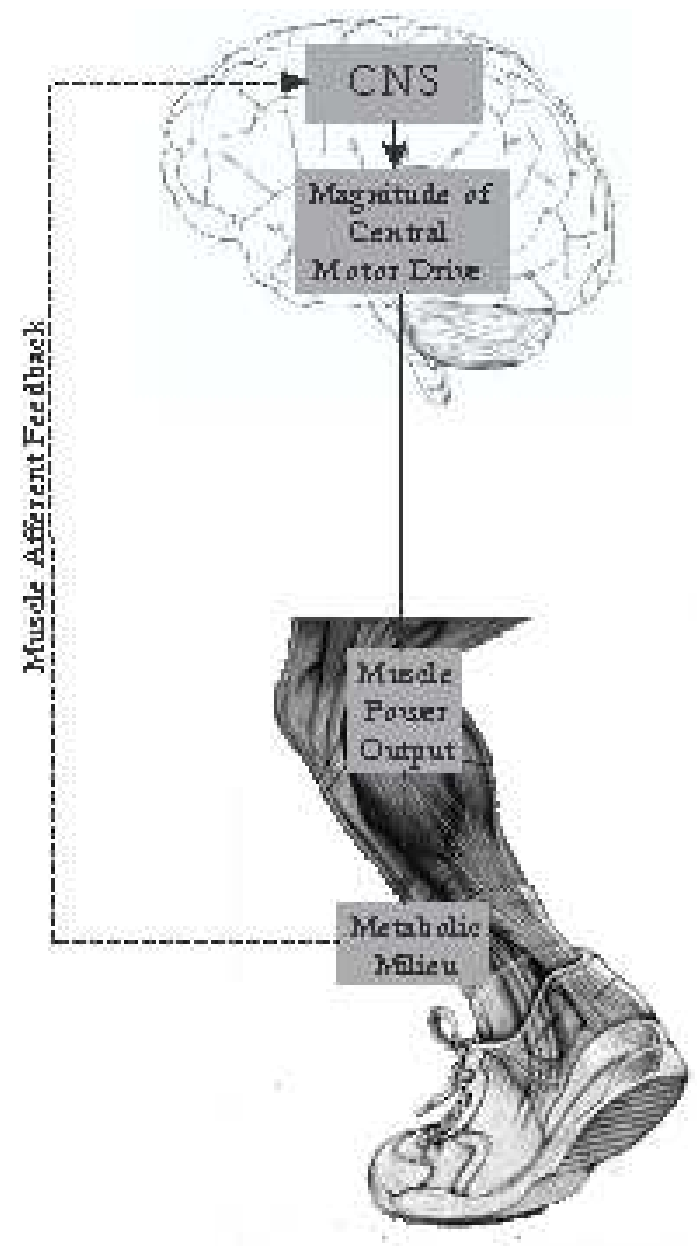

Legend: The red line represents the efferent nerve activity (central stimulation). The white dash line represents the afferent activity. This regulatory mechanism indicates that projection of muscle efferent (inhibitory feedback) affects central motor stimulation which in turn determines the power output of muscles. The size of power output determines the metabolic milieu of the active muscle, which in contrast, controls the amount of inhibitory afferent feedback.

\section{Brain areas involved in central fatigue}

Central fatigue may be stemmed from the cortex (impaired impulse in descending stimulation or de- 
creased motivation) (Taylor \& Gandevia, 2008; Taylor et al., 2006; Kent-Braun, 1999). Findings show that muscular fatigue, changes the activity of complementary and premotor regions. On the other hand, some studies found that the charge per unit of perceived exertion includes supplementary and premotor areas, primary motor cortex and the pre-visual cortex. Preoptic cortex is where recent activities are compared to the prior activities as a component of the decisionmaking process to create the sufficient intensity of contraction. Other involved areas are such as the amygdala and hippocampus (which plays a key role in emotional status), and the hypothalamus, brain stem and spinal cord, which are part of the metabolic regulatory system between afferent input and efferent commands. Cognitive activities linked to the activation of anterior cingulate cortex (ACC) may trigger central fatigue. This prefrontal cortex area plays an important role in controlling the autonomic nervous system during hard cognitive and motor activities (Marcora, Staiano, \& Manning, 2009). It also is affected by mental fatigue and provides neurobiological logic to better understand impaired motor performance after mental fatigue (Ibid). In fact, ACC activity has a relationship with exercise RPE. According to bio-psychological model of exercise performance (Ibid), and motivational intensity theory, these effects of mental fatigue can limit exercise independent of cardio-respiratory and musculo-energetic changes. consider that the prefrontal cortex is not solely involved in the planning, attention and executive and inhibitory functions, but also in working memory processes. Studies have shown that isometric contraction of the big muscle groups such as the quadriceps need frequent adaptation of force output, which is done through the information processing between the brain and peripheral system, fine motor control, executive and inhibitory processes during the contraction planning, motor visual integration and high levels of attention. High cognition effort, necessary to plan these performances, can influence the prefrontal cortex and cause to central fatigue and increased rate of perceived exertion (RPE).

\section{Synaptic and central fatigue}

Synaptic fatigue is a form of short-term activity dependent plasticity that affects the neural efficiency and cause a temporary inability to shoot and disturbed transmission of the input signal. It is thought that synaptic fatigue is a kind of negative feedback to control physiologically certain types of nervous system activities (Kilpatrick, 2010). Synaptic fatigue includes temporary inhibition of neurons because of constant and lasting stimulation in which fatigue effects are dependent on the type and frequency of the input stimuli. In fact, the reason of fatigue in the synapses is a temporary reduction of synaptic vesicles that is the position of presynaptic neurotransmitter. For signal distribution, neurotransmitters are released into post-synaptic cells. Further, it is assumed that synaptic fatigue could occur because of the reduced sensitivity of post-synaptic receptors or changes in post-synaptic conductivity. However, recent evidence has suggested that synaptic fatigue is mainly a presynaptic phenomenon (Simons-Weidenmaier, Weber, Plappert, Pilz, \& Schmid, 2006).

Acetylcholine (Ach) is a main neurotransmitter involved in the autonomic nervous system, particularly in a motor end plate (Deschenes, Maresh, \& Kraemer, 1994). In motor end plates, acetylcholine causes to the muscle contraction in small amounts, and in large amount cause inhibition of muscle contractions derived from nervous stimulation. At the neuromuscular junction (NM), there are about 50 to 70 vesicles containing Ach in per micrometer square of nerve terminals with 30 to $50 \mathrm{~nm}$ diameter. These vesicles are strategically located at neuromuscular junction in a way that Ach clusters can directly exist in all over the post-synaptic receptors (Ibid).

It is believed that Ach increases at the NMJ and cause to the inhibition of nerve stimulations during fatigue. Distinct training conditions cause different responses of Ach at NMJ. Wilson and Deschenes (2005) showed that high-intensity exercises lead more dissipation of vesicle receptors and Ach vesicle in the nerve terminal and motor end plates and thereby reduce stimulation and eventually increase fatigability. In addition, endurance exercises increase nerve terminals, pre and post-synaptic areas, while resistance trainings increase the post-synaptic area. Moreover, it has been shown that resistance exercise induced hypertrophy increases Ach at NMJ. Increased muscle size as a result of hypertrophy cause enhanced NMJ size, which in turn cause to commensurate increase in Ach for enough stimulation of more muscle fibers, so fatigue will be delayed.

\section{Neurotransmitters and central fatigue}

Clearly, training affects the neural mission of the brain (Meeusen \& De Meirleir, 1995) and increases the concentration of the various neurotransmitters (Meeusen \& Roelands, 2010). Romanowski and Grabiec (1974) associated central fatigue to the changes in transmitting brain neurotransmitters (specifically serotonin or 5-HT), while others concerned the role of dopamine (DA) and noradrenalin (NA) about the 
changes in the performance (Meeusen \& Roelands, 2010). Newsholme, Acworth, and Blomstrand (1987) suggested that fatigue was created by the increased 5-HT concentration within the brain (which decreases arousal and leads to lethargy and sleepiness). Bailey, Davis, and Ahlborn (1993) developed this hypothesis by showing the importance of the increases in DA synthesis and metabolism in the brain during the exercise. They found that fatigue is accompanied by higher levels of 5-HT and reduced dopamine in the brain stem and midbrain. Furthermore, when DA synthesis and metabolism throughout the brain are preserved, fatigue is delayed (Ibid). Manipulation of the human 5-HT could not clearly confirm these results. Some studies (Davis et al., 1993; Wilson \& Maughan, 1992) diagnosed reduced performance after administration of paroxetine and fluoxetine (reuptake inhibitors of 5-HT). However, most studies (Pannier, Bouckaert, \& Lefebvre, 1995; Parise, Bosman, Boecker, Barry, \& Tarnopolssky, 2001; Roelands et al., 2009) couldn't confirm these findings. Strüder and Weicker (2001) suggested the reduced performance capacity occurred after acute administration of 5-HT reuptake inhibitors may be as a result of the reduced functional capacity of 5-HT as a multipurpose generator that provides adaptability of neural network to address the needs of the central critical demands, not because of the increased activity of 5-HT. In addition, the researchers stated that trained athletes may be able to compensate for the excessive formation within the brain 5-HT.

About dopamine, it should be noted that early studies by amphetamines, DA releasers, have shown a significant increase in performance in both animal (Heyes, Garnett, \& Coatrs, 1985) and human (Wyndham, Rogers, Benade, \& Strydom, 1971) studies. DA neurotransmitter levels increases in order to improve the performance in the case of amphetamine administration (Borg, Edström, Linderholm, \& Marklund, 1972). However, there is evidence that brain dopamine level is similar to the resting condition during fatigue (Foley \& Fleshner, 2008) and this creates the possibility that dopamine concentration in various groups differently increases during exercise. For instance, it has been reported that inhibition of DA reuptake, increases the core temperature at the end of exercise, but has no effect on the performance in normothermia (Watson et al., 2005). Although, increased brain dopamine leads to better exercise performance (ergogenic effect) this response is associated with the increase of heat storage and body temperature (Hasegawa et al., 2008). Once dopamine effects mesolimbic reward system, it seems that by putting the inhibitory signals away from central nervous system, thermal safety domains are increased that can change perceived effort and improve exercise performance (Foley \& Fleshner, 2008; Hasegawa et al., 2008).

Furthermore, recent studies have shown that the increased noradrenalin concentration may be unfavorable for exercise performance (Roelands et al., 2008). Administration of Reboxetine, NA reuptake inhibitor, decreased performance in normothermia (Piacentini et al., 2002). The extra concentration of NA can increase sympathetic activity (Meeusen \& Roelands, 2010), but it may also result in an increased central NA reuptake inhibition within the parasympathetic nucleus that causes to reduced parasympathetic cardiac tune and enhanced heart beat (Schüle et al., 2004). The negative effect of reuptake inhibitors on performance has been detected unpredictably because it was thought that NA mechanisms were involved in arousal, awareness, and reward mechanism control of the brain (Meeusen, Watson., Hasegawa, Roelands, \& Piacentini, 2007). Through this mechanism, it can be suggested that NA has an important role in performance regulation. In other hands, it has been proved that NA neurons regulate the 5-HT system by excitatory $\alpha 1$ adrenergic receptors. In the brain stem, dorsal raphe 5-HT neurons receive ascending NA neuron afferents, which are originated from locus coeruleus (Szabo \& Blier, 2001). The role of 5-HT in central fatigue has been proved and there is both pharmacological evidence of human and animal studies (Meeusen \& Roelands, 2010) which are in line with the results have been observed after NA reuptake inhibition.

Because of the complexity of the brain function and contradictory results of the studies trying to manipulate simply serotonergic, dopaminergic or noradrenergic activity, it doesn't seem only one neurotransmitter system be responsible for central fatigue. In fact, changes of all serotonin, catecholamines, amino acid neurotransmitters (glutamate, GABA), and acetylcholine are mentioned as a possible mediator in central fatigue during exercise (Meeusen \& De Meirleir, 1995). These neurotransmitters can influence arousal, temper, motivation, awareness, stress, and reward mechanisms. In the case of being severely influenced, they disturb performance.

\section{Temperature and central fatigue}

Fatigue is a defense mechanism which prevents homeostasis disruption that puts physical integration in danger, particularly brain that is strongly capable of increased temperature (Kay \& Marino, 2000). During exercise in irrecoverable thermal pressure, 
temperature generation surpasses the body heat releasing capacity and as a result central and skin temperature increase (Cheung \& McLellan, 1998). Several studies have shown that exercise capacity in lower peripheral temperature is better (cycling to exhaustion at $70 \% \mathrm{VO}_{2} \max$ ) (Galloway \& Maughan, 1997, Parkin, Carey, Zhao, \& Febbraio, 1999). This unfavorable effect of elevated environmental temperature on performance can't be related to only peripheral and muscular factors since these factors don't change up to the amount that can explain the decrease of endurance capacity during prolonged exercise in heat (Nybo \& Secher, 2004). In some cases, muscle glycogen storage has more distances up to the depletion, muscle and blood lactate concentration isn't high comparing with exhausting exercise in normothermia and potassium release doesn't explain its induced fatigue (González-Alonso et al., 1999). In contrast, researchers suggested that during prolonged maximal voluntary contractions (MVCs), performance is decreased by central nervous system in first step under heat (Brück \& Olschewski, 1987; Nielsen et al., 1993).

In recent literature, two possible mechanisms have been mentioned, which show how hyper-thermal fatigue can limit performance (Cheung, 2007). This mechanism presupposes that approaching or achieving the higher brain and core temperature is a symptom of exhaustion development to keep the individual being knocked down. Morrison, Sleivert, and Cheung (2004) has shown a progressive central disruption associated with increased temperature. Therefore, it seems that during exercise under increased thermal pressure, high body temperature may directly or indirectly affect endurance performance. Literature review shows the existence of critical core temperature (Nielsen et al., 1993). This model is developed based on the muscular observations and equal core temperatures at the voluntary end point of exercises, with different core temperatures at the beginning and different activity time (Nielsen et al., 1993, Walters, Ryan, Tate, \& Mason, 2000). So, the body protects itself in front of potential damage. However, the concept of critical core temperature has been challenging issue recently. During competitions, some well-trained athletes may reach to the core temperature of over $40{ }^{\circ} \mathrm{C}$ (Byrne, Lee, Chew, Lim, \& Tan, 2006; $\mathrm{Ng}$, Lee, Byrne, Ho, \& Lim, 2008). Researchers have shown that in optimal environment conditions for thermal exchange in which temperature of skin remains fairly low during the $8 \mathrm{~km}$ running, achieving to the critical core temperature $\left(40^{\circ} \mathrm{C}\right)$ doesn't reduce running speed (Meeusen \& Roelands, 2010). Finally, pharmacological manipulation to increase DA has indicated along with performance improvement, core temperature of the individuals surpasses $40^{\circ} \mathrm{C}$ (Roelands et al., 2008; Watson et al., 2005). From this point of view, the critical core temperature should not be considered an all-or-none phenomenon, but it's better to be considered as a continuum with the complex interaction of various physiological systems (Meeusen \& Roelands, 2010).

The second mechanism mentions that complex feedback and feed-forward mechanisms regulate fatigue. It has been recently suggested that exercise performance in heat is controlled by the predicted response which decreases the use of involving muscles to limit temperature generation (Marino, 2004; Tucker, Rauch, Harley, \& Noakes, 2004). Feed-forward regulations of the output force may guarantee the thermal storage limit of the body to prevent developing the heat-induced illness. However, a recent article published by Shephard (2009) discusses in contrast to the existence of the central governor. Until now, lack of satisfying scientific evidence on this hypothesis and some findings such as the constant oxygen plateau in young adults has been discussed strongly in contrast to the limited role of the central governor.

Both mechanisms are probably related to each other and can be affected by the manipulation of the several neurotransmitters (Cheung, 2007). Brain monoamines 5-HT, DA, and NA innervate different areas of the hypothalamus in which there are also pre-optic and anterior hypothalamus $(\mathrm{PO} / \mathrm{AH})$. It is thought that $\mathrm{PO} / \mathrm{AH}$ is the main place of body temperature regulation (Boulant, 1974) since PO/Ah contain both kinds of cold and heat sensitive neurons. These neurons respond to the small changes of temperature (Boulant, 1974; Nakayama, Eisenman, \& Hardy, 1961). This brain region integrates the thermal data from peripheral and central thermo-receptors and begins proper heat loss and production responses. It has been well indicated that NA, and DA play important roles in regulation of the temperature in hypothalamus areas. For example, local injection of $\mathrm{NA}$ into $\mathrm{PO} / \mathrm{AH}$ in rats cause to the increase of the body temperature (Clark \& Lipton, 1986) and NA inhibits the activity of heat sensitive neurons in PO/ Ah (Watanabe, Morimoto, \& Murakami, 1986). These findings show that NA is involved in the heat production mechanism. In other hand, Quan, Xin, and Blatteis $(1991,1992)$ has shown that NA micro-dialyzed into the aware Guinea pig has stimulated the reduction of core temperature, which mediated by a decreased metabolic rate (Ibid). In addition, it has been reported that DA stimulates heat responsive neuron 
shooting rate and inhibits the cold sensitive neurons in PO/AH tissue slices (Scott \& Boulant, 1984). Furthermore, microinjection of apomorphine (an agonist of DA) into the hypothalamus of rat creates a DA mediated fall of temperature (Brown, Gisolf, \& Mora, 1982). Besides, DA release in PO/AH during the treadmill exercise was risen (Hasegawa et al., 2008), and DA caused to the increased temperature of the rats body (Myers \& Yaksh, 1968), It can be expected that changes in the concentration of these neurotransmitters, helps to the changes in temperature regulation because of fatigue, especially when the exercise is being done in the hot environment (Roelands et al., 2009).

Several studies have explored the relationship of 5-HT and temperature regulation. Local treatment of preoptic cortex and anterior hypothalamus $(\mathrm{PO} / \mathrm{AH})$ by 5 -HT caused changes in the activity of heat sensitive neurons (Watanabe et al., 1986). Feldberg and Myers (1963) have reported that injection of 5-HT into $\mathrm{PO} / \mathrm{AH}$ causes to an increase in body core temperature. Again, findings of human and animal studies indicated that how projections of pharmacological effects are difficult even when they perform in those neurotransmitters. The results don't show any role for DA releasers and 5-HT in controlling motor and central fatigue. However, any possible role of 5-HT and DA and other transmitters in motor performance should be considered as a continuum (Davis, Bailey, Jackson, Strasner, \& Morehouse, 1993). This continuum is not only important in brain level, but also in the interaction between neurotransmitters and peripheral processes in exercise such as the neurohormonal system, especially hypothalamic-pituitary-adrenal axis.

\section{Perceived exertion and central fatigue}

During the fatigue state, there needs more effort to continue a task (Taylor et al., 2006). Perceived exertion is a tool for central stimulating through corollary feedbacks into the sensory cortex. This sense reflects internal performances of increased motor order or central stimulation to continue the task (Davis \& Walsh, 2010). Brain senses the intensity of activity and environmental condition by measuring the RPE changes and coordinates duration of activity with them. Effort perception may generally be considered as a central governor, which prevents extensive damage to the muscle (Crewe, Tucker, \& Noakes, 2008). In fact, Perceived exertion is defined as a sense of neural stimulation, which is centrally produced through the prior sending of concurrent discharge or copies of efferent from motor areas into sensory areas of the brain by the corticofugal feedback system (Berchicci, Menotti, Macaluso, \& Dirusso, 2013). Therefore, locating perceived exertion and fatigue in a single area of the brain is very difficult. More probably, development of fatigue sensation is dependent on the short-term reorganization of the prefrontal motor network during the changes in the progressive model and motor awareness (Ibid). Furthermore, being aware about perceived exertion can be created prior to the movement and regardless of muscle fatigue in some areas of the brain, which are responsible for planning and motor control (frontal and prefrontal areas). Particularly, preliminary motor cortex controls the voluntary contraction and increases the movement stimulation congruent with fatigue. While, prefrontal region has an important role in creating awareness about fatigue and perceived exertion during exercise (Ibid). In other hands, reduced 5-HT production causes to the decreased circulation of 5-HT in the brain, which would be followed by the reduced sense of mental fatigue. Generally, the ratio of tryptophan to branched amine acids can be balancing in this case. So, increased dopamine production leads to a mental state that decreases perceived fatigue and increases motivation, attention and performance (Georgiades et al., 2003). Although increased brain dopamine causes to improvement of sport performance (ergogenic effect), this response is associated with increased temperature and thermal storage of the body (Hasegawa et al., 2008). Once dopamine affects the mesolimbic reward system, obviously through putting inhibitory signals away central nervous system increases safe temperature domains that can change perceived exertion and improve exercise performance (Foley \& Fleshner, 2008; Hasegawa et al., 2008). Excessive sense of exertion occurs before the tribulation in force. If an organ is weakened by neuromuscular disorder or peripheral sense be disturbed (using the use of local anesthetic or tendon vibration), perceived exertion remains unchanged in spite of the reduction of afferent signals from muscle, skin and tendons (Davis \& Walsh, 2010). During isometric contractions, perceived effort is increased as a capability of power (1.7 times of the target force) (Ibid). Furthermore, exertion sense is delayed by the psychological state of the individual. In the participants who have anxiety, depression or psychosis, RPE in the same tasks is higher and in the participants who have extrovert personality, RPE is lower (Ibid). These findings can be a bridge between fatigue and depression. Naloxone (a semi narcotic medicine, which interferes with dopamine) also increases RPE rate and decreases the time to the fatigue (Marcora et al., 2009). 


\section{CENTRAL FATIGUE IN ENDURANCE EXERCISES}

Scientists have found that in prolonged activities (such as endurance cycling and running) fatigue may occur in submaximal levels because of neural changes, which cause to the decreased central stimulations in order to protect the organism in front of extensive damage or death (Abbiss \& Laursen, 2005). Seemingly, many factors are joined in order to trigger central fatigue as a result of endurance exercise and finally to stop these activities. According to the different studies and literatures of fatigue these factors are: increased ratio of serotonin/dopamine, increased core temperature, hypoxemia, which causes to the blockage of the axon, decreased motor neuron stimulation from spinal cord parts and eventually stimulation of type III/IV muscle afferent, which will be discussed one by one with research evidence.

Ohta et al (2005) has surveyed biochemical changes during a 24-hour running, and by indirect measurement such as serum serotonin and free tryptophan have suggested that this sort of exercise causes producing supraspinal fatigue. Note that serotonin synthesis and change in CNS depends on the changes in preparation of the brain tryptophan (a responsible enzyme in catalyzing the first reaction in serotonin synthesis) (Fernstrom \& Fernstrom, 2006). Clearly, endurance exercise induced increase in plasma FFA indirectly facilitates the tryptophan influx into the brain because both compete for the same carrier (albumin) (Ibid). In other words, increased plasma free fatty acids following endurance exercise, increases the free tryptophan level. Evidence shows that more mobilization of free fatty acids in adipose tissues causes to an increase in serotonin concentration in preoptic and hypothalamus areas (Leite, Rodrigues, Soares, Marubayashi, \& Coimbra, 2010). The precursor of dopamine (tyrosine) also competes with other amino acids (including tryptophan) for entering into the brain (Foley \& Fleshner, 2008). This shows that interaction between serotonin and dopamine may be an effective issue among central fatigue factors (Foley \& Fleshner, 2008, Meeusen et al., 2007). In fact, the central fatigue hypothesis suggests that high ratio of serotonin to dopamine is associated with poor exercise performance (Ibid). This issue is important because increased serotonin activity during exercise is involved in fatigue development through inhibition of the dopaminergic system (Ibid). To support such an approach it has been shown that usage of serotonin agonists inhibited the exercise-induced increase in dopamine and treatment by the serotonin antagonists prevented the dopamine decline in the exhausted state (Foley \& Fleshner, 2008). Therefore, it seems that performance downfall is generally dependent on the increased serotonin levels which overcome dopamine ergogenic effects. A combination of such effects on the development of fatigue causes to the high ratio of hypothalamic serotonin to dopamine through central angiotensinergic inhibitors in preoptic and hypothalamus areas (Leite et al., 2010).

On the other hand, decreased serotonin level in the hippocampus is related to decreased time to the fatigue in rats with losartan treatment that suggests serotonin plays an important role in this area of the brain in controlling motor activity during exercise (Ibid).Therefore, it should be mentioned that the roles of serotonin and tryptophan differ in various areas of the brain, and it can't be said only increased brain serotonin causes the appearance of untimely fatigue. However, note that changes in serotonin and dopamine ratio have high correlation with the onset of central fatigue.

Then again, endurance activities cause an increase in metabolism and as a result generate temperature. Review of literature gives the idea of critical core temperature existence triggering central fatigue (Nielsen et al., 1993). This phenomenon has obtained from evidence in which individuals stopped the activity at the same central temperature in spite of starting at a different core temperature and getting various time trial records. Of course, it should be considered that although fatigue is often accompanied by core temperature of $40^{\circ} \mathrm{C}$, but in laboratory examinations on well trained individuals, it has been reported that the core temperature of athletes had reached to even 41 ${ }^{\circ} \mathrm{C}$ without any symptoms of heat exhaustion during sport events (Périard, Caillaud, \& Thompson, 2011). Researchers have shown that passive heating $(\mathrm{PaH})$ and hyperthermia induced during prolonged exercise $(\mathrm{ExH})$ are associated with a significant decrease in voluntary activation and force generation during MVCs (Ibid). Brain is strongly susceptible to temperature increase (Kay \& Marino, 2000) and approaching or achieving to the higher brain and core temperature is a symptom of developing exhaustion to let the body to protect itself from potential damage. Furthermore, individual's performance in endurance activities in heat is controlled by the predicted response which decreases the use of skeletal muscles to limit the temperature generation (Marino, 2004; Tucker et al., 2004). Feed-forward regulating of output force may guarantee the limitation of the body temperature storage rate to prevent developing heat induced illness. Both mechanisms cooperatively help the organism to 
protect itself from heat damage, and so it causes that athletes' performance to be limited in endurance activities.

Additionally, metabolic/pain receptor afferents (III/IV group) derived from active muscle are stimulated during sustained exercise by intramuscular metabolic byproducts (Adreani, Hill, \& Kaufman, 1997; Amann \& Secher, 2010; Light et al., 2008), and parallel to metabolite accumulation their inputs to the CNS increases. This central projection, reflectively causes an increase in blood flow (blood pressure increasing reflex due to blood vessel contraction during exercise) and ventilation (Kaufman \& Forster, 1996) and gradually decreases $\mathrm{CMO} /$ voluntary activation of muscle and so central fatigue is increased (Gandevia, 2001). Once lower limb muscles' central projection is blocked by the medicine (L3/L4), the performance of the experimental group was significantly increased compared with the placebo group during a time trial $5 \mathrm{~km}$-cycling and subjects went over their critical threshold of peripheral fatigue (Amann \& Dempsey, 2008). Blocking the muscle afferent, released the break of central CMO and CNS tolerated muscular fatigue in a way that it reached about $44 \%$ over than what observed in the placebo group. Also, higher peripheral fatigue by this method was associated with motor problems (Ibid).

Evidence points out that the onset of peripheral fatigue of muscle during sustained exercise is exclusive to the individual's critical threshold and sensory tolerance range, which increases by the individual's will (Amann, Romer, Subudhi, Pegelow, \& Dempsey, 2007; Duhamel, Green, Sandiford, Perco, \& Ouyang, 2004; Gagnon et al., 2009). This means that during efforts with a constant load, when peripheral fatigue reaches to the crucial threshold (probably dependent on the task), the exercise reaches to the end either voluntarily or CMO doesn't have efficiency for continuing the task. For example, following the electrical stimulation of the quadriceps of healthy individuals to create peripheral fatigue, the time of cycling with fixed load up to the failure, was lower than the control group (who only cycled without electric stimulation of their muscles). However, at the failure point of both groups, tiredness of quadriceps and individual's perception of thigh fatigue was equal (Gagnon et al., 2009). These studies confirmed the research previously done using a time trial (instead of fixed load). During time trials after quadriceps fatigue, $\mathrm{CMO}$ was significantly lower and the time for crossing the finish line was more. Even so, quadriceps fatigue and individual's perception of this fatigue were equal at the end of the trial, which shows that $\mathrm{CMO}$ is adapted according to the peripheral condition of active muscle (Amann \& Dempsey, 2008). About the trials with fixed load, once an individual reaches the critical threshold; the endurance exercise is voluntarily reached to the end or about the exercise with a time trial, when the critical fatigue (or critical change rate in an intracellular metabolic environment) was created; the intensity of the activity gets decreased by a drop in CMD. The scientists have hypothesized that CNS processes the nervous feedback derived from the active muscle afferents and regulates the exercise, according to $\mathrm{CMD}$ to prevent developing peripheral fatigue more than the critical threshold since the otherwise sensory input would be intolerable (Amann \& Dempsey, 2008, Amann et al., 2006).

The effects of peripheral and central disruptions in CMD (and consequently, exercise) are changed by oxygenation of the brain (Amann et al., 2007). In a recent work, participants were asked to exercise with the fixed load (333 \pm w) and high-intensity up to the exhaustion in normoxia (activity up to the exhaustion $\approx 10 \mathrm{~min}$, hemoglobin saturation in exhaustion $\approx 93$ $\%$ ) and acute hypoxia $(\approx 2 \mathrm{~min}, \approx 67 \%)$. When the participants stopped the exercise in normoxia condition, peripheral fatigue reached to the participants' critical threshold (Ibid). In contrast, when participants stopped the task in hypoxia condition, peripheral fatigue of the active muscles was significant, but it was only two third of the amount that was recorded for normoxia group, and thus it was very lower than the individual's critical threshold (Ibid). In other words, participants could store more fatigue, but they stopped the exercise before a critical threshold. In this condition, when researchers secretly changed the breathing gases into the combination of supplemental oxygen (30\% oxygen, hyperoxia) during exhaustion of the normoxia subjects, they couldn't continue the task. In contrast, when researchers stealthily used the complementary oxygen for hypoxia-exhausted participants, all of them continued the task up to reach the critical threshold (Ibid).

About developing the central fatigue, fewer studies have explored the kinetics of maximal voluntary activation during the multijoint movements. Lepers, Millet, and Maffiuletti (2001), and Place, Lepers, Deley, and Millet (2004) have measured VA in every hour of 5 hours running and cycling with normal intensity. Both groups of researchers have reported a reduction of VA simply close to the end of the activity. Ross, Goodall, Stevens, and Harris (2010) has recently measured maximal voluntary activation in knee extensors in every $5 \mathrm{~km}$ during a $20 \mathrm{~km}$ running on treadmill and reported just a significant reduction 
after $20 \mathrm{th} \mathrm{km}$. Since in most of the studies, VA reduction was accompanied with exhaustion, probably we can conclude that VA reduction is the main factor of the individual's inability to maintain the required intensity of the activity.

In addition, the existence of the plateau or reduction in motor stimulation, which have been reported at the end of the task (Ibid) are very likely independent of the changes in the various muscular junction or sarcolemma stimulation because $\mathrm{M}$ wave properties didn't change during the protocol. Therefore, it seems that when inability in contraction reaches to a critical point or when the increase rates of motor stimulation get to the certain level, no increase would occur in central orders seemingly to prevent more contraction disruption or because of the fact, that inability to increase motor stimulation during intensive activities is due to the brain disruption (central fatigue).

Study of peripheral and central fatigue kinetics during high-intensity cycling showed that peripheral fatigue occurs in the preliminary steps of cycling, and individual compensates this fatigue by more motor stimulation, while central fatigue is accompanied by failure in a task and happens at the last stages of the activity (Decorte, Lafaix, Millet, Wuyam, \& Verges, 2012). Therefore, it can be mentioned that it's not only central fatigue that determines the athletes' performance in endurance activities, but also different factors such as temperature, oxygen and substrate availability, metabolites..., cause to peripheral fatigue, and it facilitates the central fatigue development and at the end to stop the exercise. In addition, Millet (2011) investigated neuromuscular fatigue in super marathon running in a review study and concluded that both peripheral and central fatigue have an important role in determining the exercise performance, and both have interaction with each other (Millet, 2011).

\section{CENTRAL FATIGUE IN RESISTANCE EXERCISES}

Clearly, several causes are involved in triggering central fatigue as a result of resistance exercises and finally to stop these activities. According to different studies and literature, these factors are such as reduction of EMG activity because of the decrease in frequency of the recruited motor unit shooting, the role of post-synaptic membrane, depletion of neurotransmitters and stimulation of type III/IV afferents, which will be explored by giving research evidence.

According to different studies, it can be inferred the origin of fatigue depends on the muscular activ- ity form and angular speed of the movement (Babault, Desbrosses, Fabre, Michaut, \& Pousson, 2006). Most of the studies have examined the effect of isometric contraction on central fatigue development. For example, Berchicci et al. (2013) asked the participants to perform 242 isometric contractions with their quadriceps muscle of the right foot by $40 \%$ of their MVC using optical feedback on force output provided by an oscilloscope. These movements finally led to the fatigue. It seems that the isometric contraction of the big muscle groups such as the quadriceps requires frequent coordination of output force done through the process of the information between brain and peripheral system, frail kinetic control, motorvisual integration and high levels of attention. Frequent isometric contractions affect the monotonic state of the intramuscular environment that cause developing fatigue sense. Therefore, developed peripheral fatigue during this task incorporates with the central fatigue created by higher cognitive processes, which requires performing the proper task and needs emotional factors such as attention and arousal levels. Observed activity in the prefrontal area of the fatigued group who reported higher RPE was probably the result of high cognitive effort, which is necessary for planning these actions (Ibid). Prefrontal area is not involved only in planning, attention and inhibitory and executive tasks, but also in working memory processes. Studies have shown that conscious perception of fatigue is derived from the prefrontal area where the recent activities are compared with the prior activities as a part of the decision-making process to create adequate intensity of the contraction. Other involved regions such as the amygdala and hippocampus (that have key roles in an emotional condition), hypothalamus, brain stem, and spinal cord, are parts of the metabolic regulatory system between afferent inputs and efferent orders (Ibid). So, it seems that one of the factors involved in fatigue development during isometric contraction is over activity of the prefrontal cortex, which has an important role in the RPE. According to the literature of the central fatigue, higher RPE reduces the activation of the motor units and so the output force to relieve the organism from severe threatening changes that put its health at risk.

In other hands, strong isometric contraction causes the blockage of active muscle's blood vessels that leads to ischemia, hypoxemia, and accumulation of metabolic byproducts such as lactate and therefore, increases the rate of the shooting type III and IV afferent (Adreani et al., 1997; Amann \& Secher, 2010; Light et al., 2008). As previously mentioned, stimulation of metabolic/pain receptor afferents gradually 
decreases $\mathrm{CMO} /$ voluntary activation of the muscles and increases the central fatigue (Gandevia, 2001). Remember that experienced strength athletes can highly recruit their muscles, which leads to more central fatigue in forced repetitions (Ahtiainen \& Hakkinen, 2009). In addition, the RPE in strength exercises and isometric contractions can be generated without involving muscle afferent feedback system, but in a feed-forward way through simultaneous sending of a copy of afferent from the motor to the sensory area of the brain (Berchicci et al., 2013). When this perceived exertion goes over the critical rate, $\mathrm{CNS}$ or central governor would reduce the stimulation of motor units, and central fatigue would be observed.

Performing prolonged isometric contractions or frequent electric stimulation can reduce end plate potentials (EPPs) and decreases the output force because of either reduction in the numbers of vesicles or each vesicle's acetylcholine content or both. In addition, researchers have concluded the major reason of EPPs decrease during the continuous stimulation is decreased sensitivity of end motor plates and not because of the transmitters' evacuation. It seems that because of frequent concentric or isometric contractions the receptors exposing acetylcholine for a long time, first become susceptible to nonsensitiveness and then face with a nonsensitive state which its characteristic is a slow and a shorter period of each attachment.

About the other types of contracts, Robbins, Goodale, Docherty, Behm, and Tran (2010) studied fatigue indices in descending pattern (DP), in which repetitions were decreased the next sets, and ascending pattern (AP), in which repetitions were increased in the following sets. Both patterns were done under the loads of 5 and 10 maximal repetitions. Fatigue was studied by monitoring the output force changes, motor unit activation, and muscle twitch properties, peak twitch (PT), time to peak twitch (TPT) and halflife of the relaxation time (RT). The findings showed that all four protocols created a significant decline in force output, TPT and RT. The findings of the study showed that central fatigue is independent of load and training pattern while the onset of peripheral fatigue is more dependent on training load not training pattern. In contrast, Babault et al. (2006) suggested that as a result of concentric training, peripheral fatigue develops first and then central fatigue occurs following that, while in isometric training, fatigue pattern is vice versa (first central and then peripheral fatigue occurs).

\section{CONCLUSION}

Based on the different mechanisms during resistant and endurance exercises and findings of various studies, researchers suggest central fatigue happens in both kinds of activities. However, the mechanisms of fatigue development and the RPE are distinct in each of them (mentally, endurance exercises are more difficult). Study of the fatigue kinetics shows that first peripheral fatigue occurs and CNS tries to prevent disturbing output force by activating more motor units. Once peripheral fatigue goes over the certain rate, nervous system reduces activation of motor units to prevent extensive disruption in homeostasis and muscle damage and protect the central governor, which is strongly sensitive to temperature, and thereby central fatigue happens. Still, in important and critical situations such as the final stages of running a marathon (when the last flight of runners is observed) and fight-or-flight situations in which someone faces a worse outcome if a task is abandoned, humans can choose one of worse and the worst alternatives to write their final destiny.

\section{REFERENCES}

Abbiss, C. R., \& Laursen, P. B. (2005). Models to Explain Fatigue during Prolonged Endurance Cycling. Sports Med, 35(10), 865-898. doi: 10.2165/00007256-200535100-00004

Adreani, C. M., Hill, J. M., \& Kaufman, M. P. (1997). Responses of group III and IV muscle afferents to dynamic exercise. Journal of Applied Physiology, 82(6), 1811-1817. PMid: 9173945

Ahtiainen, J. P., \& Hakkinen, K. (2009). Strength Athletes Are Capable to Produce Greater Muscle Activation and Neural Fatigue During High-Intensity Resistance Exercise Than Nonathletes. Journal of Strength \& Conditioning Research, 23(4), 1129-1134. doi: 10.1519/ JSC.0b013e3181aa1b72; PMid: 19528869

Amannn, M., \& Dempsey, J. A. (2008). Locomotor muscle fatigue modifies central motor drive in healthy humans and imposes a limitation to exercise performance. The Journal of Physiology, 586(Pt 1), 161-173. doi: 10.1113/ jphysiol.2007.141838; PMid: 17962334; PMCid: PMC2375542

Amann, M., Eldridge, M., Lovering, A., Stickland, M., Pegelow, D., \& Dempsey, J. (2006). Arterial oxygenation influences central motor output and exercise performance via effects on peripheral locomotor muscle fatigue. The Journal 
of Physiology, 575(Pt 3), 937-952. doi: 10.1113/ jphysiol.2006.113936; PMid: 16793898; PMCid: PMC1995675

Amann, M., Romer, L. M., Subudgi, A. W., Pegelow, D. F., \& Dempsey, J. A. (2007). Severity of arterial hypoxaemia affects the relative contributions of peripheral muscle fatigue to exercise performance in healthy humans. The Journal of Physiology, 581, 389-403. doi: 10.1113/ jphysiol.2007.129700; PMid: 17317739; PMCid: PMC2075206

Amann, M., \& Secher, N. H. (2010). Point: Afferent feedback from fatigued locomotor muscles is an important determinant of endurance exercise performance. Journal of Applied Physiology, 108(2), 452-454. doi: 10.1152/japplphysiol.01386.2009; doi: 10.1152/japplphysiol.00976.2009; PMid: 19729588

Babault, N., Desbrosses, K., Fabbre, M. S., Michaut, A., \& Pousson, M. (2006). Neuromuscular fatigue development during maximal concentric and isometric knee extensions. Journal of Applied Physiology, 100(3), 780-785. doi: 10.1152/ japplphysiol.00737.2005; PMid: 16282433

Bailey, S. P., Davis, J. M., \& Ahlborn, E. N. (1993). Neuroendocrine and substrate responses to altered brain 5-HT activity during prolonged exercise to fatigue. Journal of Applied Physiology, 74(6), 3006-3012. PMid: 8366000

Berchicci, M., Menotti, F., Macaluso, A., \& Dirusso, F. (2013). The neurophysiology of central and peripheral fatigue during sub-maximal lowerlimb isometric contractions. Frontiersin Human Neuroscience, 7, 1-10. doi: 10.3389/ fnhum.2013.00135; PMid: 23596408; PMCid: PMC3625743

Bergström, J., Hermansen, L., Hultman, E., \& Saltin, B. (1967). Diet, muscle glycogen and physical performance. Acta Physiologica Scandinavica, 71(2-3), 140-150. doi: 10.1111/j.1748-1716.1967.tb03720.x; PMid: 5584523

Borg, G., Edström, C. G., Linderholm, H., \& Marklund, G. (1972). Changes in physical performance induced by amphetamine and amobarbital. Psychopharmacologia, 26(1), 10-18. doi: 10.1007/BF00421914

Boukant, J. (1974). The effect of firing rate on preoptic neuronal thermosensitivity. The Journal of Physiology, 240(1), 661-669.

Brown, S., Gisolfi, C., \& Mora, F. (1982).

Temperature regulation and dopaminergic systems in the brain: does the substantia nigra play a role? Brain Res, 234, 275-286. doi: 10.1016/0006-8993(82)90868-X

Bruck, K., \& Olschewski, H. (1987). Body temperature related factors diminishing the drive to exercise. Canadian journal of physiology and pharmacology, 65(6), 1274-1280. doi: 10.1139/ y87-203

Byrne, C., Lee, J., Chew, S. A. N., Lim, C. L., \& Tan, E. (2006). Continuous thermoregulatory responses to mass-participation distance running in heat. Medicine and Science in Sports and Exercise, 38(3), 803-810. doi: 10.1249/01. mss.0000218134.74238.6a; PMid: 16672830

Cheung, S. S. (2007). Hyperthermia and voluntary exhaustion: integrating models and future challenges. Applied Physiology, Nutrition, and Metabolism, 32(4), 808-817. doi: 10.1139/H07043; PMid: 17622299

Cheung, S. S., \& Mclellan, T. M. (1998). Heat acclimation, aerobic fitness, and hydration effects on tolerance during uncompensable heat stress. Journal of Applied Physiology, 84(5), 1731-1739. doi: 10.1007/s004210050386

Clark, W. G., \& Lipton, J. (1986). Changes in body temperature after administration of adrenergic and serotonergic agents and related drugs including antidepressants: II. Neuroscience \& Biobehavioral Reviews, 10(2), 153-220. doi: 10.1016/0149-7634(86)90025-4

Crewe, H., Tucker, R., \& Noakes, T. 2008. The rate of increase in rating of perceived exertion predicts the duration of exercise to fatigue at a fixed power output in different environmental conditions. Eur I Appl Physiol Occup Physiol, 103, 569-577. doi: 10.1007/s00421-008-0741-7; PMid: 18461352

Davis, J., Bailey, S., Jackson, D., Strasner, A., \& Morehouse, S. (1993). 438 Effects of A Serotonin (5-Ht) Agonist During Prolonged Exercise to Fatigue in Humans. Medicine \& Science in Sports \& Exercise, 25(5), S78. doi: 10.1249/00005768-199305001-00440

Davis, M. P., \& Walsh, D. (2010). Mechanisms of Fatigue. I Support Oncol, 8(4), 164-174. PMid: 20822034

Decorte, N., Lafaix, P. A., Millet, G. Y., Wuyam, B., \& Verges, S. (2012). Central and peripheral fatigue kinetics during exhaustive constant-load cycling. Scand J Med Sci Sports, 22(3), 381-391. doi: 10.1111/j.1600-0838.2010.01167.x; PMid: 20807390

Desschenes, M. R., Maresh, C. M., \& Kraemer, W. J. (1994). The Neuromuscular Junction: Structure function, and its role in the Excitation of 
Muscle. The Journal of Strength and Conditioning Research, 8(2), 103-109. doi: 10.1519/00124278199405000-00008; doi: 10.1519/1533-4287 (1994)008<0103:TNJSFA>2.3.CO;2

Dobkin, B. 2008. Fatigue versus activity-dependent fatigability in patients with central or peripheral motor impairments. Neurorehabil Neural Repair, 22(2), 105-110. doi: 10.1177/15459683083 15046; PMid: 18285599; PMCid: PMC4160309

Duhamel, T. A., Green, H. J., Sandiford, S. D., Perco, J. G., \& Ouyang, J. (2004). Effects of progressive exercise and hypoxia on human muscle sarcoplasmic reticulum function. Journal of Applied Physiology, 97, 188-196. doi: 10.1152/ japplphysiol.00954.2003; doi: 10.1152/ japplphysiol.00958.2003; PMid: 15064300

Fernstrom, J., \& Fernstrom, M. (2006). Exercise, serum free tryptophan, and central fatigue. $J$ Nutr, 136(2), 553S-559S. PMid: 16424146

Foley, T., \& Fleshner, M. (2008). Neuroplasticity of dopamine circuits after exercise: implications for central fatigue. Neuromolecular Med, 10(2), 67-80. doi: 10.1007/s12017-008-8032-3; PMid: 18274707

Gadnon, P., Saey, D., Vivodtzev, I., Laviolette, L., Mainguy, V., Milot, J., ... Maltais, F. (2009). Impact of preinduced quadriceps fatigue on exercise response in chronic obstructive pulmonary disease and healthy subjects. Journal of Applied Physiology, 107, 832-840. doi: 10.1152/japplphysiol.91546.2008; PMid: 19574500

Galloway, S., \& Maughan, R. J. (1997). Effects of ambient temperature on the capacity to perform prolonged cycle exercise in man. Medicine and Science in Sports and Exercise, 29(9), 1240-1249. doi: 10.1097/00005768-199709000-00018

Gandevia, S. 2001. Spinal and supraspinal factors in human muscle fatigue. Physiol Rev, 81(4), 1725-1789. PMid: 11581501

Georgiades, E., Beham, W., Kilduff, L., Hadjicharalambous, M., Mackie, E., Wilson, J., ... Pitsiladis, Y. (2003). Chronic fatigue syndrome: new evidence for a central fatigue disorder. Clinical Sciences, 105(2), 213-218. doi: 10.1042/ CS20020354; PMid: 12708966

Gibson, S. C., Lambert, M., \& Noakes, T. (2001). Neural control of force output during maximal and submaximal exercise. Sports Med, 31(9), 637-650. doi: 10.2165/00007256-20013109000001

González-Alonso, J., \& Calbet, J. A. (2003). Reductions in systemic and skeletal muscle blood flow and oxygen delivery limit maximal aerobic capacity in humans. Circulation, 107(6), 824-830. doi: 10.1161/01. CIR.0000049746.29175.3F

González-Alonso, J., Teller, C., Andersen, S. L., Jensen, F. B., Hylding, T., \& Nikelsen, B. (1999). Influence of body temperature on the development of fatigue during prolonged exercise in the heat. Journal of Applied Physiology, 86, 1032-1039. PMid: 10066720

Hargreaves, M., \& Febbraio, M. (1998). Limits to exercise performance in the heat. International journal of sports medicine, 19(Suppl. 2), S115-S116. doi: 10.1055/s-2007-971973; PMid: 9694414

Hasegawa, H., Piacentini, M., Sarre, S., Michotte, Y., Ishiwata, T., \& Meeusen, R. (2008). Influence of brain catecholamines on the development of fatigue in exercising rats in the heat. J Physiol, 586(Pt 1), 141-149. doi: 10.1113/ jphysiol.2007.142190; PMid: 17947314; PMCid: PMC2375558

Heyes, M., Garnett, E., \& Coates, G. (1985). Central dopaminergic activity influences rats ability to exercise. Life sciences, 36(7), 671-677. doi: 10.1016/0024-3205(85)90172-9

Kaufman, M. P., \& Forster, H. V. (1996). Reflexes controlling circulatory, ventilatory and airway responses to exercise. In L. Rowell and J. T. Shepherd (Eds.), Handbook of Physiology, section 12, Exercise: Regulation and Integration of Multiple Systems (pp. 381-447). Oxford, NY: University Press.

Kay, D., \& Marino, F. (2000). Fluid ingestion and exercise hyperthermia: implications for performance, thermoregulation, metabolism and the development of fatigue. J Sports Sci Med, 18(2), 71-82.

Kent-Braun, J. (1999). Central and peripheral contributions to muscle fatigue in humans during sustained maximal effort. Eur J Appl Physiol Occup Physiol, 80(1), 57-63. doi: 10.1007/ s004210050558; PMid: 10367724

Kilpatrick, Z. P. (2010). Spatially structured waves and oscillations in neuronal networks with synaptic depression and adaptation. Unpublish doctoral thesis, University of Utah.

Leite, L. H. R., Rodrigues, A. G., Soares, D. D., Marubayashi, U., \& Coimbra, C. N. C. (2010). Central Fatigue Induced by Losartan Involves Brain Serotonin and Dopamine Content. Medicine \& Science in Sports \& Exercise. doi: 10.1249/ MSS.0b013e3181d03d36; PMid: 20068491

Lepers, R., Millet, G., \& Maffiuletti, N. (2001). Effect of cycling cadence on contractile and neural properties of knee extensors. Med Sci 
Sports Exerc, 33(11), 1882-1888. doi: 10.1097/00005768-200111000-00013

Light, A. R., Hughen, R. W., Zhang, J., Rainier, J., Liu, Z., \& Lee, J. (2008). Dorsal root ganglion neurons innervating skeletal muscle respond to physiological combinations of protons, ATP, and lactate mediated by ASIC, P2X, and TRPV1. Journal of neurophysiology, 100, 1184-1201. doi: 10.1152/jn.01344.2007; PMid: 18509077

Marcora, S. M., Staiano, W., \& Manning, V. (2009). Mental fatigue impairs physical performance in humans. J Appl Physiol, 106(3), 857-864. doi: 10.1152/japplphysiol.91324.2008; PMid: 19131473

Marino, F. E. 2004. Anticipatory regulation and avoidance of catastrophe during exerciseinduced hyperthermia. Comparative Biochemistry and Physiology Part B: Biochemistry and Molecular Biology, 139(4), 561-569. doi: 10.1016/j. cbpc.2004.09.010; PMid: 15581788

Meeusen, R., \& De Meirleir, K. (1995). Exercise and brain neurotransmission. Sports Medicine, 20(3), 160-188. doi: 10.2165/00007256199520030-00004

Meeusen, R., \& Roelands, B. (2010). Central fatigue and neurotransmitters, can thermoregulation be manipulated? Scandinavian journal of medicine \& science in sports, 20(3), 19-28. doi: 10.1111/j. 1600-0838.2010.01205.x; PMid: 21029187

Meeusen, R., Watson, P., Hasegawa, H., Roelands, B., \& Piacentini, M. (2007). Brain neurotransmitters in fatigue and overtraining. Appl Physiol Nutr Metab, 32(5), 857-864. doi: 10.1139/H07-080; PMid: 18059610

Millet, G. Y. (2011). Can neuromuscular fatigue explain running strategies and performance in ultra-marathons? Sports Medicine, 41(6), 489-506. doi: 10.2165/11588760-000000000-00000; PMid: 21615190

Morrison, S., Sleivert, G. G., \& Cheung, S. S. (2004). Passive hyperthermia reduces voluntary activation and isometric force production. European journal of applied physiology, 91(5-6), 729-736. doi: 10.1007/s00421-004-1063-z; PMid: 15015001

Myers, R., \& Yaksh, T. (1968). Feeding and temperature responses in the unrestrained rat after injections of cholinergic and aminergic substances into the cerebral ventricles. Physiology \& Behavior, 3, 917-928. doi: 10.1016/00319384(68)90178-9

Nakayama, T., Eisenman, J., \& Hardy, J. (1961). Single unit activity of anterior hypothalamus during local heating. Science, 134(3478), 560-561. doi: 10.1126/science.134.3478.560; PMid: 13727681

Newsholme, E. A., Acworth, I. N., \& Blomstrand, E. (1987). Amino acids, brain neurotransmitters and a functional link between muscle and brain that is important in sustained exercise. In G.Benzi (Ed.), Advances in Biochemistry (pp. 127-138). Glasgow, United Kingdom: John Libbey Eurotext. Ng, Q. Y., Lee, K. W., Byrne, C., Ho, T. F., \& Lim, C. L. (2008). Plasma endotoxin and immune responses during a 21$\mathrm{km}$ road race under a warm and humid environment. Annals-Academy of Medicine Singapore, 37(4), 307-314.

Nielsen, B., Hales, J., Strange, S., Christensen, N. J., Warberg, J. \& Saltin, B. (1993). Human circulatory and thermoregulatory adaptations with heat acclimation and exercise in a hot, dry environment. The Journal of Physiology, 460, 467-485. doi: 10.1113/jphysiol.1993.sp019482

Noakes, T. (2000). Physiological models to understand exercise fatigue and the adaptations that predict or enhance athletic performance. Scandinavian journal of medicine \& science in sports, 10(3), 123-145. doi: 10.1034/j.1600-0838. 2000.010003123.x

Noakes, T. D., Gibson, A. S. C., \& Lambert, E. V. (2005). From catastrophe to complexity: a novel model of model of integrative central neural regulation of effort and fatigue during exercise in humans: summary and conclusions. Br J Sports Med, 39(4), 120-124. doi: 10.1136/

bjsm.2003.010330; PMid: 15665213; PMCid: PMC1725112

Nybo, L., \& Secher, N. H. (2004). Cerebral perturbations provoked by prolonged exercise. Progress in neurobiology, 72(4), 223-261. doi: 10.1016/j.pneurobio.2004.03.005; PMid: 15142684

Ohta, M., Hirai, N., Ono, Y., Ohara, M., Saito, S., Horiguchi, S., ... Andou, T. (2005). Clinical biochemical evaluation of central fatigue with 24-hour continuous exercise. Rinsho byori. The Japanese journal of clinical pathology, 53(9), 802-809.

Pannier, J., Bouckaert, J., \& Lefebvre, R. (1995). The antiserotonin agent pizotifen does not increase endurance performance in humans. European journal of applied physiology and occupational physiology, 72(1-2), 175-178. doi: 10.1007/BF00964134

Parise, G., Bosman, M. J., Boecker, D. R., Barry, M. J., \& Tarnopolsky, M. A. (2001). Selective 
serotonin reuptake inhibitors: their effect on high-intensity exercise performance. Archives of physical medicine and rehabilitation, 82(7), 867-871. doi: 10.1053/apmr.2001.23275; PMid: 11441370

Parkin, J., Carey, M., Zhao, S., \& Febbraio, M. (1999). Effect of ambient temperature on human skeletal muscle metabolism during fatiguing submaximal exercise. Journal of Applied Physiology, 86(3), 902-908. PMid: 10066703

Periard, J. D., Caillaud, C., \& Thompson, M. W. (2011). Central and peripheral fatigue during passive and exercise-induced hyperthermia. Med Sci Sports Exerc, 43(9), 1657-1665. doi: 10.1249/ MSS.0b013e3182148a9a; PMid: 21364487

Piacentini, M. F., Meeusen, R., Buyse, L., De Schutter, G., Kempenaers, F., Van Nijvel, J., \& De Meirleir, K. (2002). No effect of a noradrenergic reuptake inhibitor on performance in trained cyclists. Medicine and Science in Sports and Exercise, 34, 1189-1193. doi: 10.1097/00005768-200207000-00021; PMid: 12131261

Place, N., Lepers, R., Deley, G., \& Millet, G. (2004). Time course of neuromuscular alterations during a prolonged running exercise. Med Sci Sports Exerc, 36(8), 1347-1356. doi: 10.1249/01. MSS.0000135786.22996.77

Quan, N., Xin, L., \& Blatteis, C. M. (1991). Microdialysis of norepinephrine into preoptic area of guinea pigs: characteristics of hypothermic effect. American Journal of PhysiologyRegulatory, Integrative and Comparative Physiology, 261(2 30-2), R378-R385.

Quan, N., Xin, L., Ungar, A., \& Blatteis, C. (1992). Preoptic norepinephrine-induced hypothermia is mediated by alpha 2-adrenoceptors. American Journal of Physiology-Regulatory, Integrative and Comparative Physiology, $262(3$ 31-3), R407-R411.

Robbins, D. W., Goodale, T. L., Docherty, D., Behm, D. G., \& Tran, Q. T. (2010). The Effects of Load and Training Pattern on Acute

Neuromuscular Responses in the Upper Body. Journal of Strength \& Conditioning Research, 24(11), 2996-3007. doi: 10.1519/

JSC.0b013e3181f67474; PMid: 20975369

Roelands, B., Goekint, M., Buyse, L., Pauwels, F., De Schutter, G., Piacentini, F., ... Meeusen, R. (2009). Time trial performance in normal and high ambient temperature: is there a role for 5-HT? European journal of applied physiology, 107(1), 119-126. doi: 10.1007/s00421-0091109-3; PMid: 19533165

Roelands, B., Goekint, M., Heyman, E., Piacentini, M. F., Watson, P., Hasegawa, ... Meeusen, R.
(2008). Acute norepinephrine reuptake inhibition decreases performance in normal and high ambient temperature. Journal of Applied Physiology, 105(1), 206-212. doi: 10.1152/ japplphysiol.90509.2008; PMid: 18499777

Romanowski, W., \& Grabiec, S. (1974). The role of serotonin in the mechanism of central fatigue. Acta Physiol Pol., 25(2), 127-134, PMid: 4830711

Ross, E., Goodall, S., Stevens, A., \& Harris, I.

(2010). Time course of neuromuscular changes during running in well-trained subjects. Med Sci Sports Exerc, 42(6), 1184-1190. PMid: 19997016

Ross, E. Z., Middleton, N., Shave, R., George, K., \& Nowicky, A. (2007). Corticomotor excitability contributes to neuromuscular fatigue following marathon running in man. Exp Physiol, 92(2), 417-426. doi: 10.1113/expphysiol.2006.035972; PMid: 17099060

Rowell, L., Marx, H., Bruce, R., Conn, R., \& Kusumi, F. (1966). Reductions in cardiac output, central blood volume, and stroke volume with thermal stress in normal men during exercise. Journal of Clinical Investigation, 45(11), 1801-1816 doi: 10.1172/JCI105484; PMid: 5926447; PMCid: PMC292862.

Schule, C., Baghai, T., Schmidbauer, S., Bidlingmaier, M., Strasburger, C. J., \& Laakmann, G. (2004). Reboxetine acutely stimulates cortisol, ACTH, growth hormone and prolactin secretion in healthy male subjects. Psychoneuroendocrinology, 29(2), 185-200. doi: 10.1016/S0306-4530(03)00022-2

Scott, I., \& Boulant, J. (1984). Dopamine effects on thermosensitive neurons in hypothalamic tissue slices. Brain Res, 306(1-2), 157-163. doi: 10.1016/0006-8993(84)90364-0

Shephard, R. J. (2009). Is it Time to Retire the 'Central Governor'? Sports Medicine, 39(9), 709-721. doi: 10.2165/11315130-00000000000000; PMid: 19691362

Simons-Weidenmaier, N. S., Weber, M., Plappert, C. F., Pilz, P. K. D., \& Schmid, S. (2006). Synaptic depression and short-term habituation are located in the sensory part of the mammalian startle pathway. BMC Neuroscience, 7(1), 38. doi: 10.1186/1471-2202-7-38; PMid: 16684348; PMCid: PMC1479352

Struder, H., \& Weicker, H. (2001). Physiology and pathophysiology of the serotonergic system and its implications on mental and physical performance. Part I. International journal of sports medicine, 22(7), 467-481. doi: 10.1055/s-2001 -17605; doi: 10.1055/s-2001-17606 
Szabo, S. T., \& Blier, P. (2001). Functional and pharmacological characterization of the modulatory role of serotonin on the firing activity of locus coeruleus norepinephrine neurons. Brain Res, 922(1), 9-20. doi: 10.1016/ S0006-8993(01)03121-3

Taylor, J., Todd, G., \& Gandevia, S. (2006). Evidence for a supraspinal contribution to human muscle fatigue. Clin Exp Pharmacol Physiol, 33(4), 400-405. doi: 10.1111/j.14401681.2006.04363.x; PMid: 16620309

Taylor, J., \& Gandevia, S. (2008). A comparison of central aspects of fatigue in submaximal and maximal voluntary contractions. J Appl Physiol, 104(2), 542-550. doi: 10.1152/ japplphysiol.01053.2007; PMid: 18032577

Tucker, R., Rauch, L., Harley, Y. X., \& Noakes, T. D. (2004). Impaired exercise performance in the heat is associated with an anticipatory reduction in skeletal muscle recruitment. Pflügers Archiv, 448(4), 422-430. doi: 10.1007/s00424-0041267-4; PMid: 15138825

Walters, T., Rzyn, K., Tate, L., \& Mason, P. (2000). Exercise in the heat is limited by a critical internal temperature. Journal of Applied Physiology, 89(2), 799-806. PMid: 10926668
Watanabe, T., Morimoto, A., \& Murakami, N. (1986). Effect of amine on temperatureresponsive neuron in slice preparation of rat brain stem. American Journal of PhysiologyRegulatory, Integrative and Comparative Physiology, 250, R553-R559.

Watson, P., Hasagawa, H., Roelands, B., Piacentini, M. F., Looverie, R., \& Meeusen, R. (2005). Acute dopamine/noradrenaline reuptake inhibition enhances human exercise performance in warm, but not temperate conditions. The Journal of Physiology, 565(3), 873-883. doi: 10.1113/jphysiol.2004.079202; PMid: 15831540; PMCid: PMC1464564

Wilson, M., \& Deschenes, M. (2005). The neuromuscular junction: anatomical features and adaptations to various forms of increased, or decreased neuromuscular activity. The international journal of neuroscience, 115(6), 803-828. doi: 10.1080/00207450590882172; PMid: 16019575

Wyndham, C., Rogers, G., Benade, A., \& Strydom, N. (1971). Physiological effects of the amphetamines during exercise. $S$ Afr Med J, 45(10), 247-252. PMid: 5573329

Received: October 5, 2014

Revision received: December 7, 2014

Accepted: December 26, 2014

Correspondence to: Mostafa Khani

Department of Physical Education and Sports Sciences, Ahar Branch, Islamic Azad University, Ahar, East Azerbaijan, IRAN. Phone: 00989149263371

Fax: 00984135569950 Email:m-khani@iau-ahar.ac.ir 